\title{
Project-based learning in the teaching-learning process university. A longitudinal study
}

\author{
Leyla Angélica Sandoval Hamón ${ }^{1 a}$, Fernando Casani ${ }^{1}$, Jesus Pomeda-Rodriguez ${ }^{1}$, and \\ Ricado Olmos Albacete ${ }^{2}$ \\ ${ }^{1}$ Autonomous University of Madrid, Faculty of Economics and Business Studies, Madrid 28049. \\ Spain. \\ ${ }^{2}$ Autonomous University of Madrid, Faculty of Psychology, Madrid 28049. Spain.
}

\begin{abstract}
The European Higher Education Area promotes the change in teaching-learning, where students have a more active role in their educational process. The main objective of this work is to analyse the use of an alternative proposal, focus in student-based teamwork activities, who seek to favour the acquisition and deepening of knowledge and skills. The implementation of this research was carried out by means of a longitudinal study in the subject of the degree of Economics, with the development of the methodology of Project Based Learning integrating the ICTs and improving the evaluation process (e.g. establishing headings and psychometric analysis of knowledge tests). The results of the research showed an improvement in the learning process from the observation, collection of works, analysis of knowledge tests and the official survey by students to assess the activity and the development of their competitors. Keywords: Project-Based Learning; ICTs; Evaluation; Higher Education.
\end{abstract}

\section{Introduction}

The European Higher Education Area has presented a new university context that seeks to respond to the challenges of European educational convergence, with modifications that affect each of the elements that make up the teaching-learning process. Consequently, the changes are not only directed to learning, competencies, teaching methodologies or the incorporation of technologies, but also to transformations "in the evaluation, in all its approaches: object, agents, moments; as well as in the instruments and techniques that enable their implementation"[1].

This work focuses on analysing the use of an alternative methodology to the traditional one (project based learning), while promoting the use of information and communication technologies (ICTs); and taking into account the adaptation to this change in regard to the way in which the subject is evaluated.

From the above, some definitions are indicated that have served as a point of reference throughout the course:

a Corresponding author: angelica.sandoval@uam.es 
Project-Based Learning: PBL is a learning and teaching approach that makes students search for new knowledge and skills, helps them overcome real-life questions, and makes them design their own studies and performances"[2]. The "need to know / need to do" principle also drives the learning process and inspires them to delve deeper into concepts [3]. Students are involved in learning authentic themes, asking questions, raising hypotheses, searching for relevant information, planning an inquiry, collecting data, thinking critically, discussing, sharing ideas, reasoning and decision-making, developing a product, and presenting it to an audience. [4].

Furthermore, PBL applications also contribute to equipping students with 21 st century skills, identified as critical thinking, problem solving, creativity, access to and restructuring of information, usage of digital resources, taking responsibility, sharing ideas, self-control and reconciliation [5].

The use of ICTs in education according to UNESCO contributes, among other things, to equality in education, the exercise of quality teaching and learning and the professional development of teachers, as well as the management of more efficient management and administration of the educational system.

With regards to evaluation strategies, two main groups can be classified: traditional strategies (open and closed knowledge tests, work, projects and oral exams) to which summative assessment and innovative strategies are associated (self-evaluation, Portfolios, techniques of observation ...) that are associated to the formative evaluation.

In short, the literature indicates that using an active methodology (such as PBL) requires going hand in hand with an adaptation of the evaluation. This makes sense, considering that assessment is "the most powerful weapon teachers have in influencing how students respond to courses and behave as students" [6].

\section{Method}

\subsection{Contextualization -Research Group}

- Degree: Economy

- Course: Fourth grade. First semester academic year.

- Academic years: 2014-2015, 2015-2016, 2016-2017.

- Subject: Seminar of Business Administration (ADE in advance) and Socio-Political Environment.

- $\mathrm{N}^{\mathrm{o}}$ Credits: 6 (150 hours)

- Total students: 110

- Course objective: This seminar aims to bring the student to fully comprehend the functioning reality of the economic system and the behavior of companies.

\subsection{Design and development}

Before beginning the first semester of each academic year part of the study, the teaching team of the subject met and planned all the class sessions sharing with the students (including the time of work outside of class). To verify that the students fulfilled the tasks proposed, they always had to make a delivery or presentation of some material to go evaluating the evolution of the construction of their knowledge.

The content was related to the development of two projects in teamwork (five students per team) throughout the course, one related to the analysis of a sector of activity and another specifically with the analysis of a company of the sector in order to use ICTs. 
Table 1. Methodologies / Evaluation and their corresponding tasks.

\begin{tabular}{lll}
\hline Phase & Description & \multicolumn{1}{c}{ Tasks } \\
\hline 1 & Project & 1.1 Preparation of proposals \\
& 1.2 Planning and instructions for doing the \\
& projects & 1.3 Project monitoring \\
& 1.4 Verification of results \\
& 1.5 Evaluation of results \\
\hline & ICTs & (Listing) \\
& 2.2 Share resources with students and \\
& influence how to use them with the proposed \\
& active methodology. \\
& 2.3 Promote the use of ICTs. \\
& 2.4 Supporting students in the use of ICTs. \\
& 3.1 Elaboration of rubrics for the two projects \\
& (Company and Sector). \\
& 3.2 Elaboration of two knowledge tests (peer- \\
& reviewed). \\
& 3.3 Psychometric analysis of knowledge tests \\
& (Test Analysis Program, TAP). \\
& 3.5 Students' evaluation questionnaire on the \\
& methodology, resources and form of \\
& assessment of the subject. \\
&
\end{tabular}

In line with the development of the active methodology (PBL) and with the process of change of the subject, the teachers adapted the evaluation, in such a way that the students:

(a) knew in advance the evaluation criteria of the activities and once delivered projects easily recognise their strengths and weaknesses, according to teacher guidelines and feedback, and

(b) have an aggregated test of knowledge testing.

\subsection{Data Collection}

The process of collecting information on the use of the PBL methodology, the incorporation of ICTs and the adaptation of the evaluation was integrated by different sources:

A source came from the continuous development of the two projects (where two deliveries of final reports were received and presented to the class, where the use of new ICTs was evidenced) and the behaviour of the team, both aspects are considered in the Items that were provided.

Another source that was considered was the summative evaluation, where, once the knowledge tests were adapted (two tests), in total 110 students completed them in the three academic courses. The results of the knowledge tests were taken as reference for the psychometric analysis.

\subsection{Analysis of the Data}

Statistical analysis was performed using the Test Analysis Program (TAP) software and complemented with SPSS v21. The TAP program addressed psychometric analysis. Cronbach's Alpha coefficient was used to assess the quality of the tests in terms of their 
reliability. In order to examine the quality of the items, the indices of difficulty and discrimination were used.

In particular, six test-type knowledge tests with 32 questions each and four response options were analysed. The tests are 2014 (two of them), 2015 (two others) and 2016 (the last two). With this psychometric study we tried to find out if there was an improvement in the reliability and the psychometric properties of the questions as an evolution to the good practices developed in the preparation of exams.

\section{Results and suggestions}

Psychometric analysis of the knowledge tests mentioned.

The following table shows the reliability coefficients of the six exams, the average difficulty of the questions (understood as proportion of hits on the total answers), the average discrimination of the questions (high discrimination indices inform that multiple choice questions distinguish between less and high competent students), and the number of students.

Table 1. Data of the psychometric analysis performed

\begin{tabular}{clcccc}
\hline Year & Test & Coefficient $\boldsymbol{\alpha}$ & Difficulty & Discrimination & N \\
\hline \multirow{2}{*}{2014} & Test 1 & 0,583 & 0,613 & 0,276 & 39 \\
\cline { 2 - 5 } & Test 2 & 0,763 & 0,837 & 0,278 & \\
\hline \multirow{2}{*}{2015} & Test 1 & 0,533 & 0,646 & 0,212 & \multirow{2}{*}{36} \\
\cline { 2 - 5 } & Test 2 & 0,664 & 0,798 & 0,264 & \\
\hline \multirow{2}{*}{2016} & Test 1 & 0,719 & 0,564 & 0,378 & 35 \\
\cline { 2 - 5 } & Test 2 & 0,752 & 0,818 & 0,307 & \\
\hline
\end{tabular}

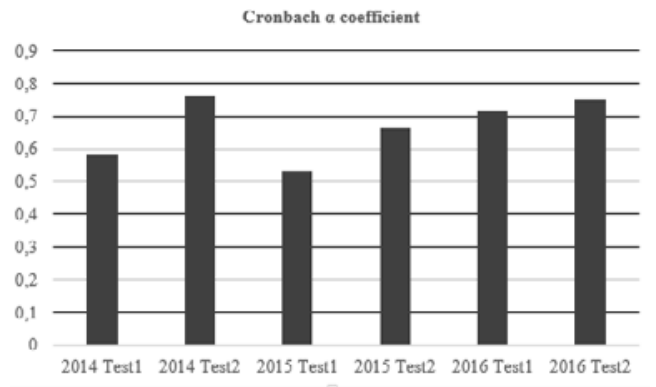

Fig. 1. Test reliability coefficients.

These results show that in the last two courses the two tests analysed exceeded the reliability of 0.70 (cut off usually used to consider that a knowledge test measures accurately). In the previous years, only in 2014 a test exceeded this value. In addition, the average discrimination of the questions exceeded the value 0.30 only in the two exams of 2016 , sign that the questions were elaborated correctly and with the capacity to distinguish between the more and less competent students. Probably, the 2016 results are due to the fact that two judges independently examined the quality of the questions. The sample size was similar between the different exams.

The results in general indicate that the use of the active methodology (PBL), the favouring of the ICT and the adaptation of the evaluation have been positive for the construction of the learning, this is evidenced on the one hand by the psychometric analysis of the tests of knowledge that shows.

In short, the changes in the methodology of the subject have been useful, because it has been advanced in that the students are better prepared, not only in the theoretical knowledge 
about the organizations, but in that they are also able to act in them of and integrate ICTs in a practical, useful, responsible and ethical way. Evidence of this significant advance has been the improvement in the grades obtained by the students and, in addition, by the satisfaction shown by these with the subject (collected in the official survey conducted).

\section{References}

[1] M. . I. B. Alsina, F. Á. C. Rodríguez, "Estrategias de evaluación de los aprendizajes centradas en el proceso," Rev. Esp. Pedagog., vol. 59, no. 218, pp. 25-48, (2001).

[2] O. D. Baysura, S. Altun, B. Yucel-Toy, "Perceptions of Teacher Candidates regarding Project-Based Learning," Eurasian J. Educ. Res., no. 62, pp. 15-36, (2016).

[3] S. Jacques, S. Bissey, A. Martin, "Multidisciplinary Project Based Learning Within a Collaborative Framework: A Case Study on Urban Drone Conception," Int. J. Emerg. Technol. Learn. IJET, vol. 11, no. 12, p. 36, Dec. (2016).

[4] O. Goldstein, "A project-based learning approach to teaching physics for pre-service elementary school teacher education students," Cogent Educ., vol. 3, p. UNSP 1200833, (2016).

[5] S. Bell, "Project-Based Learning for the 21st Century: Skills for the Future," Clear. House J. Educ. Strateg. Issues Ideas, vol. 83, no. 2, pp. 39-43, Jan. (2010).

[6] Gibbs, G., Uso estratégico de la educación en el aprendizaje. Evaluar en la universidad: problemas y nuevos enfoque. Narcea, (2003). 